\title{
The Advisory Roles of Political Scientists in Comparative Perspective
}

Arco Timmermans, Marleen Brans, and José Real-Dato

\subsection{INTRODUCTION}

In most European countries, political scientists based at universities perform other tasks than research and education alone. They also engage in advisory activities. Advising is a multidimensional enterprise, varying along the communication chain from sender to receiver in viewpoints, knowledge base and aim, format, content and targeted actor. Advising can be constructed strongly on the basis of scientific evidence and result from the orientation that, in an advisory role, academics must stay close to the objective knowledge and truth about their object of study. It also can be

\author{
A. Timmermans $(\bowtie)$ \\ Institute of Public Administration, Leiden University, Leiden, Netherlands \\ e-mail: a.timmermans@fgga.leidenuniv.nl \\ M. Brans \\ Public Governance Institute, KU Leuven, Leuven, Belgium \\ e-mail: marleen.brans@kuleuven.be \\ J. Real-Dato \\ University of Almería, Almería, Spain \\ e-mail: jreal@ual.es \\ (C) The Author(s) 2022 \\ M. Brans, A. Timmermans (eds.), The Advisory Roles of Political \\ Scientists in Europe, \\ https://doi.org/10.1007/978-3-030-86005-9_16
}


constructed by academics who not only want to analyse and explain but also express beliefs that the functioning of government must be improved, democracy needs innovation, or some policy problems and social groups obtain too little attention, and others too much.

Political scientists as advisers thus can keep distance from their objects of study or choose to engage with political actors or other stakeholders in the policy process. They even may try to set the political agenda through such engagement. It is impossible and also undesirable to derive one uniform type of 'best' and 'most justified' advisory role for political scientists as a group of academics. This was our point of departure in this book, and the general observation that political scientists across European countries engage to different degrees and in various ways underlines the importance of this neutral stance. The advisory orientations and activities of political scientists not only result from personal conviction but also are contingent on the domestic academic structures, the policy advisory system, and broader developments in politics and society.

The twelve country chapters in this book all considered the same set of questions on the advisory roles of political scientists. What roles do they take? How do they look at any work at the intersection of the university home basis and the political and social environment? How do evidence, facts, normative beliefs and advocacy enter into choice-making? And which driving factors play a significant role when political scientists differ in gender, age and status of their employment at the university? The first next section of this chapter presents the main findings for 39 countries, at an aggregate level, using the pooled data of the entire ProSEPS international survey project. How are the advisory role types distributed, and what is the effect of individual background variables such as gender, age and status of work contrast for the extent of engagement? Then in Sect. 16.3 we discuss how countries are similar or different in the patterns observed. In this comparative section, we consider the responses to the survey questions as operationalizations of the different dimensions of advising. Given the chapters in this book with in-depth country studies, we use these 12 countries in the comparison. Such a first comparison of advisory orientations and behaviour across European countries cannot be exhaustive given the multitude of variables that may play a part. For this reason, the focus is on how countries with a number of features in common compare to other countries, and how in this way patterns of advisory activity may be placed in context, which is the central focus of Sect. 16.4. 
Then in Sect. 16.5 we return to the advisory role types and the simple two-dimensional model used to assess their occurrence. The findings of our joint comparative project on the different other dimensions of advising lead us to examine how it may be possible to move beyond the simple model of advisory activities of academic political scientists. What interpretations can we make, what inferences can we draw from the aggregate findings on style, form and recipients for the four ideal typical roles? What do these findings tell us about the characteristics of the pure academic, the expert, the opinionating scholar and the public intellectual? How may we further develop these types? This is the point where our approach with a basic model and analysis of a broader range of findings can inform further theory building and conceptual generalization beyond the academic political science community. The final Sect. 16.6 is an outlook not only on further inquiry but also on possible implications of our comparative work for the professionalization of political science in Europe in the years to come.

\subsection{The General Picture Emerging from the Survey Project}

The picture emerging from the overall survey data is that the majority of university-based political scientists in Europe can be categorized as opinionating scholars. This not only is the most frequent advisory type, it also occurs more frequent than the pure academic who refrains from engagement. Figure 16.1 shows the percentages of each of the four types of political scientists. Almost one out of two political scientists $(48.7 \%)$ in our sample belongs to the category of opinionating scholar, with experts coming second at a distance $(26.6 \%)$. Just over one-fifth $(20.3 \%)$ stays away from advising as a pure academic, and, as expected, the all-round profile of public intellectual applies to only a small group (4.4\%) of political scientists.

A first conclusion is thus that on average, political scientists in Europe are more extrovert in their behaviour as academics than is sometimes thought. In their professional functioning they live outside the ivory tower' for some part of their time and tasks, delivering knowledge and information messages to practitioners in the policy process. They are oriented to a significant degree on 'entrepreneurial relevance' (Timmermans et al., 2021). Often these messages contain analytical viewpoints and recommendations, and even more often they bring normative statements on 


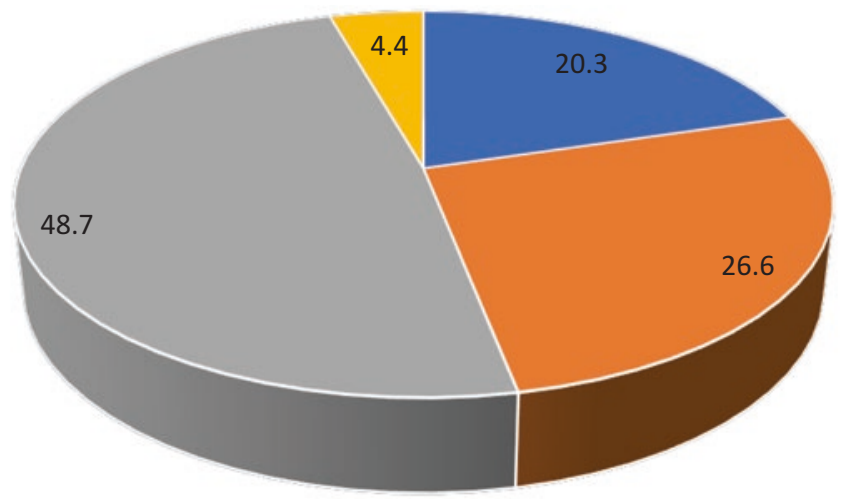

- Pure academic $\quad$ Expert $\square$ Opinionating scholar $\square$ Public intellectual

Fig. 16.1 Policy advisory types of European political scientists (\%) $N=2354$. (Source: ProSEPS survey data)

politics and policy problems or speak the language of advocacy. European political scientists do not appear to fear the power to which they speak truth, and engage in all kinds of interaction with policy-making institutions or other stakeholders in the policy process. Though this does not mean that academic political scientists collectively go political or do this continually, it is clear that next to scientific evidence, also values and normative beliefs play a part when they engage. This first main finding is important as it may indicate tendencies within the academic community of political scientists and within the policy advisory systems in Europe. The object of study and advice itself may have become more politicized, or at least politically sensitive, and it also may be that advising from diverse locations within the policy advisory system is in a process of mediatization. The prominence of opinionating may testify to such a tendency.

\subsubsection{The Non-unitary State of Political Scientists in Europe}

This major finding, however, may not apply equally to all countries in Europe. Hence we must look at the pattern across countries. Figure 16.2 displays the proportions of advisory role types for all 39 countries in the ProSEPS project. It appears that the pure academic is a much rarer breed in some countries than in others. In Albania, Belgium, Denmark, Norway, 


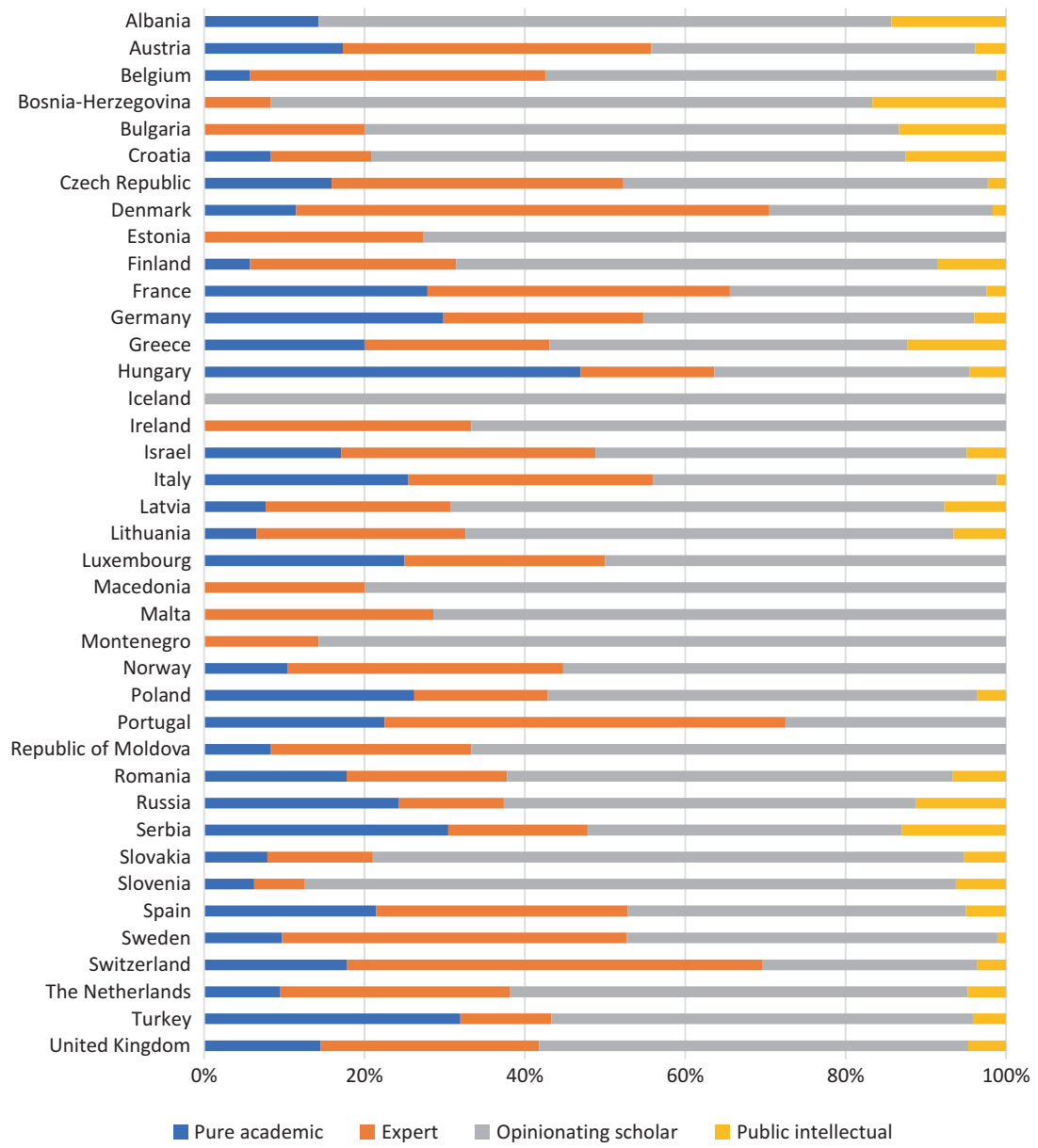

Fig. 16.2 Policy advisory roles of political scientists by country $(N=2354)$. (Source: ProSEPS survey data)

the Netherlands and the United Kingdom, relatively few political scientists are of this kind, while in France, Germany, Italy and particularly in Hungary and Turkey there is a higher proportion of the scholarly political science community abstaining from active engagement. This pattern is contingent on considerably higher levels of advisory activity in the first group of countries, and lower levels in the second group. What stands out 
is that in the two countries with the largest proportion of pure academics, Hungary and Turkey, opinionating scholars far outnumber experts. This suggests a divide between political scientists who stay mostly within the academic sphere and those who make explicit normative statements and engage in advocacy.

Countries with few pure academics fall into two categories: those where experts are relatively prominent (Belgium, Norway and in particular Denmark), and those where opinionating scholars take the lead (Albania, the Netherlands and the United Kingdom). From the countries not examined more closely in this book, it is striking that former communist states and also Malta have a higher or much higher proportion of opinionating political scientists. With the exception of Malta, these countries also have a higher percentage of public intellectuals than in the European average, and some even have no pure academics within the group of respondents in the survey. Actors running the government and politics of these countries thus seem to stir opinionating contributions from scholars studying them. In some of these countries, political scientists also have previous or ongoing external affiliations that bring some kind of political or professional commitment (see Chap. 3 where positions outside academia are presented and discussed). Finally, Germany and the United Kingdom, the two countries with the largest population of political scientists, differ mainly in one respect: the comparatively larger number of pure academics in Germany $(29.8 \%)$ suppresses the proportion of opinionating colleagues $(41.3 \%)$ in that country, while in the United Kingdom space for opinionating (53.5\%) is opened by the lower salience of the role of pure academic (14.6\%).

In short, the academic political science community in Europe is not uniform across countries in the extent and types of advisory roles taken. This is not a surprising finding, given the diversity in history, institutionalization of the discipline and developing relationships between policymaking institutions and academia. The patterns we find across countries reflect these contextual factors, which will be further addressed later in this chapter.

\subsubsection{Effects of Gender, Age and Job Status}

A second main perspective on advisory roles is through the lens of background variables. The country chapters have shown that such variables as gender, age and work contract matter. Sometimes, the effect of such factors is intended or official policy. But often, the way in which gender, age 
and work contract impacts on the activities of academics, and certainly on external professional activities, is unintended. Causes of engagement or nonengagement are inadvertent. Or indeed, it may be that there is not even a clear picture of how individual characteristics as basic as gender and age have an effect on the professional performance and career development of academics at all.

Let us begin with the aggregate picture of gender composition of academic political scientists in the four role types. Just over 33\% of the sample in this survey project indicates a female gender. This is certainly an underrepresentation compared to the overall population of European countries-as is the case in many professions-but it is representative of the total population of political scientists at universities in Europe, and only slightly lower than in the World of Political Science survey conducted in 2019, which had a global scope (Norris, 2020).

Be this as it may, there is a clear pattern in the gender composition of role types: as we move from the pure academic to the limitedly exposed expert on to the more exposed opinionating scholar and further to the public intellectual, the percentage with a female gender drops consistently. As Table 16.1 shows, a bit over $39.2 \%$ of the pure academics is female, but this goes down $20.2 \%$ of the public intellectuals, with experts and opinionating scholars in between.

What are the main findings on the average age of political scientists in role types? Our aggregate data tell us that age variation across the types is limited: pure academics are around 43 years old on average, while experts are nearly three years older and also opinionating scholars and public intellectuals both are just above 47 years old. The average age just above mid-40 is the result of just over $75 \%$ of the respondents being born until 1980 , and just under $25 \%$ after 1980 . As with gender, the percentages of these two groups change consistently with role types: of the pure

Table 16.1 Policy advisory types by gender

\begin{tabular}{llll}
\hline & Female (\%) & Male (\%) & Prefer not to say (\%) \\
\hline Pure academic & 39.2 & 58.2 & 2.5 \\
Expert & 36.9 & 60.7 & 2.4 \\
Opinionating scholar & 28.6 & 69.6 & 1.8 \\
Public intellectual & 20.2 & 78.8 & 1.0 \\
Total & 33.3 & 64.6 & 2.1 \\
\hline
\end{tabular}

Source: ProSEPS survey data 
academics, $37.2 \%$ is born after 1980 , and this goes down to $24.8 \%$ of the experts, $18.7 \%$ of opinionating scholars and $21.2 \%$ of the public intellectuals.

This points to a professional life cycle effect, in which different ages are associated with different types and degrees of advising. Professional accomplishments and consolidation of expertise may enable political scientists to assume and perform more roles. Important to realize here is that in this project on advisory views and activities, the target population consists of scholars already at or beyond the stage of obtaining a $\mathrm{PhD}$ and/or with substantive teaching tasks within their university department. The first stage, earliest career scholars thus were not included in the survey. This also explains that even pure academics were, on average, already above 40 years old on average.

A third factor bringing more depth in our understanding of advisory role performance is employment status. This relates in part to the professional life cycle, but apart from work mobility that may involve more than one tenure track as scholars move from one university to the other, a temporary or permanent contract usually is decided relatively early on in an academic career. And again, the pattern we observe is consistent to subsequent role types, noting that the sample consists almost entirely of post$\mathrm{PhD}$ scholars. If on average for all political scientists almost $28.7 \%$ has a temporary and $71.3 \%$ a permanent contract, pure academics face more job uncertainty, as they have a permanent contract in only $59.6 \%$ of the cases. For experts this is $70.6 \%$, opinionating scholars have permanent work in $76 \%$ of the cases, and public intellectuals in $77.2 \%$. These, however, are all relative figures. The majority of pure academics, certainly when no longer in their earliest career stage, have a permanent contract at any of the political science departments in Europe (or sometimes an affiliation elsewhere as well). This is a relevant observation for understanding the role perception of pure academics: when they refrain from active advisory engagement, it is not only for reasons of job security.

\subsection{Unpacking the Dimensions of Advising}

The distribution of advisory role types of political scientists in Europe is based on the simple two-dimensional model in which different advising activities represent types of knowledge (episteme, techne and phronesis), and an ordinal scale is used for the frequency of each of these activities. 
The percentages of role types within countries and the pooled data for all countries are generated on this basis. When looking into this model for all countries together, we find that overall and presented in Fig. 16.3, delivering forecasts and poll results to policy makers is practised the least, and analysing and explaining causes and consequences of policy problems is the type of advice provided most often. Both are expert matters (and forecasting and polling even are for specialists) but problem analysis also may come in combination with other types and in this way also can be part of the repertoire of opinionating scholars and public intellectuals. The other kinds of activity are between the lowest and highest frequency of delivery, and in different combinations they fill the role types of all. Thus, the frequent provision of data and facts is more typically expert business, while ongoing contacts for evaluation, consultancy and recommendations may bring political scientists closer to more outspoken role types if they link this to normative statements or advocacy. That a majority of academic political scientists does not step back from sometimes or more often making value judgements and normative arguments is a key indicator of the sizeable group of opinionating scholars.

I make value-judgements and normative arguments $(\mathrm{N}=2177)$

I make forecasts and/or carry out polls ( $\mathrm{N}=2158)$

I offer consultancy services and advice, and make recommendations on policy alternatives $(\mathrm{N}=2209)$

I evaluate existing, policies, institutional arrangements, etc. $(\mathrm{N}=2217)$

I analyse and explain the causes and consequences

of policy problems $(\mathrm{N}=2238)$
I provide data and facts about policies and political
phenomena $(\mathrm{N}=2233)$

of policy problems $(\mathrm{N}=2238)$
I provide data and facts about policies and political
phenomena $(\mathrm{N}=2233)$

of policy problems $(\mathrm{N}=2238)$
I provide data and facts about policies and political
phenomena $(\mathrm{N}=2233)$
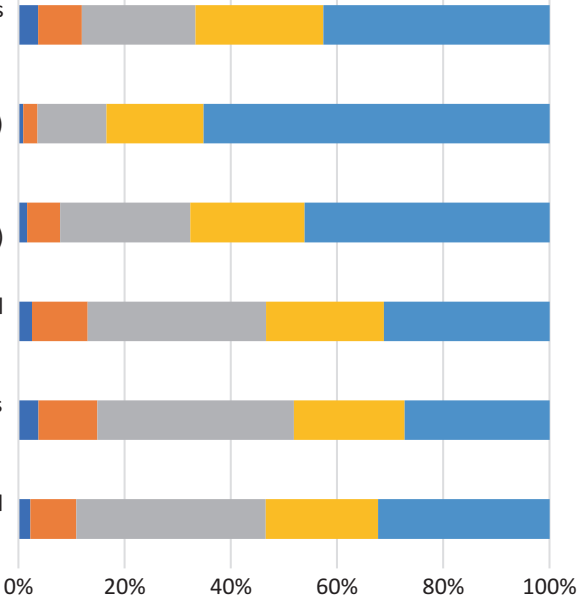

At least once a week $\square$ At least once a month $\square$ At least once a year $\square$ Less frequently $\square$ Never

Fig. 16.3 Frequency of advising activities. (Source: ProSEPS survey data) 


\subsubsection{Why Political Scientists Engage}

Given the composition of our crossnational sample of political scientists, targeted to include scholars who are no longer in their earliest career stage, most fit some advisory role type. Pure academics comprise one-fifth of the respondents on average, with variation between countries from $0 \%$ to above $40 \%$. For various reasons among which some job uncertainty, these academics do not engage. Asked about underlying views, indeed also about one-fifth of all European political scientists agree entirely or partly that political scientists should refrain from direct engagement with policy actors. But as Fig. 16.4 also shows, most agree fully or to an extent that their knowledge has a role to play in practice, that visibility in public debate belongs to their professional obligation, or that they must directly engage with policy makers themselves. As with the different advising activities, this points to an open orientation on expertise delivery or opinionating.

Intrinsic or extrinsic motivations also play a part. Professional and public role performance appear more important than instrumental considerations such as funding opportunities or career advancement. Figure 16.5 entails deliberate selection in the generation of viewpoints here, as only respondents who do engage in advising were asked what motivates them. An overwhelming majority believes that making a contribution to society

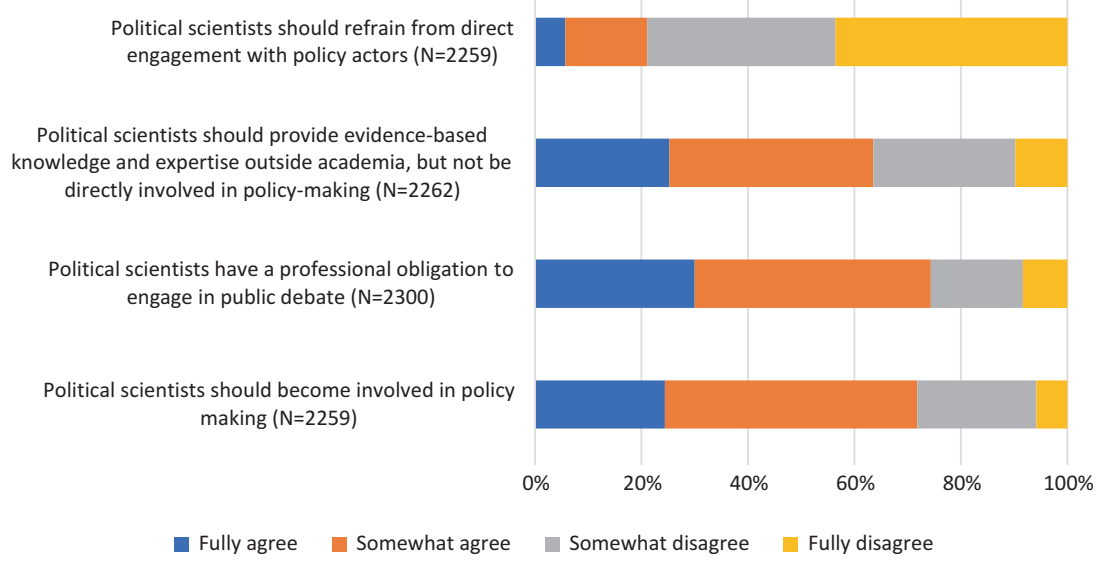

Fig. 16.4 Desirability of engagement. (Source: ProSEPS survey data) 
I like to make a contribution to society ( $N=1794)$

Engagement in advisory or consulting activities is part of my professional duty as a political scientist $(\mathrm{N}=1784)$

It helps expand my career options and provides alternative sources of finance $(\mathrm{N}=1781)$

It helps advance my academic career $(\mathrm{N}=1770)$

I like to stay active minded ( $\mathrm{N}=1755)$
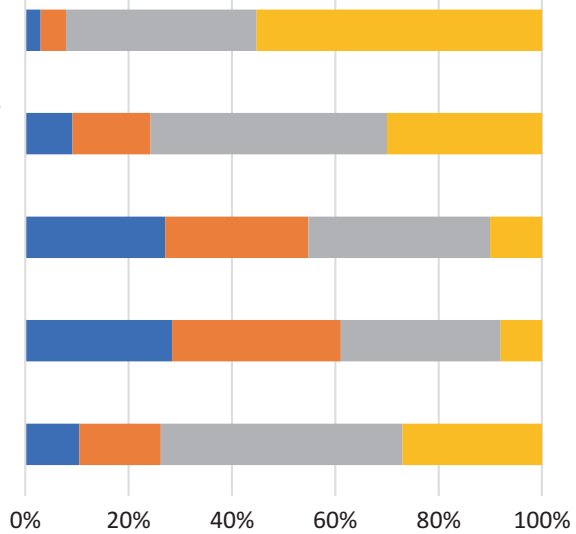

not important at all $\quad$ Somewhat unimportant

Somewhat important $\square$ Absolutely important

Fig. 16.5 Motivations for engagement. (Source: ProSEPS survey data)

is important and that advising helps to stay active minded. And duty weighs heavier than academic position or research money coming from this external source.

\subsubsection{The Flow of Advice}

Two next dimensions of advising are the channels used and the recipients who solicit advice or are targeted by political scientists themselves. While the most traditional and typical form of knowledge dissemination for academics is via (scientific or semi-scientific) publications, advising requires also other channels or formats. These are included in Fig. 16.6. Easily produced, flexible and accessible channels are used more frequently in advising than publications, but for each of these channels the group of political scientists never using them (between $18.2 \%$ and $38.3 \%$ ) also is larger than for publications (14.0\%). This suggests that we deal with academics in advisory roles, not with professional advisors located elsewhere who are not so occupied with writing publications. However, visible in Fig. 16.6 is the opinionating role: when used, writing traditional media articles, blogs or social media entries happens more often at a monthly or even weekly interval compared to the use of other channels, which also require more investment in time and effort. 


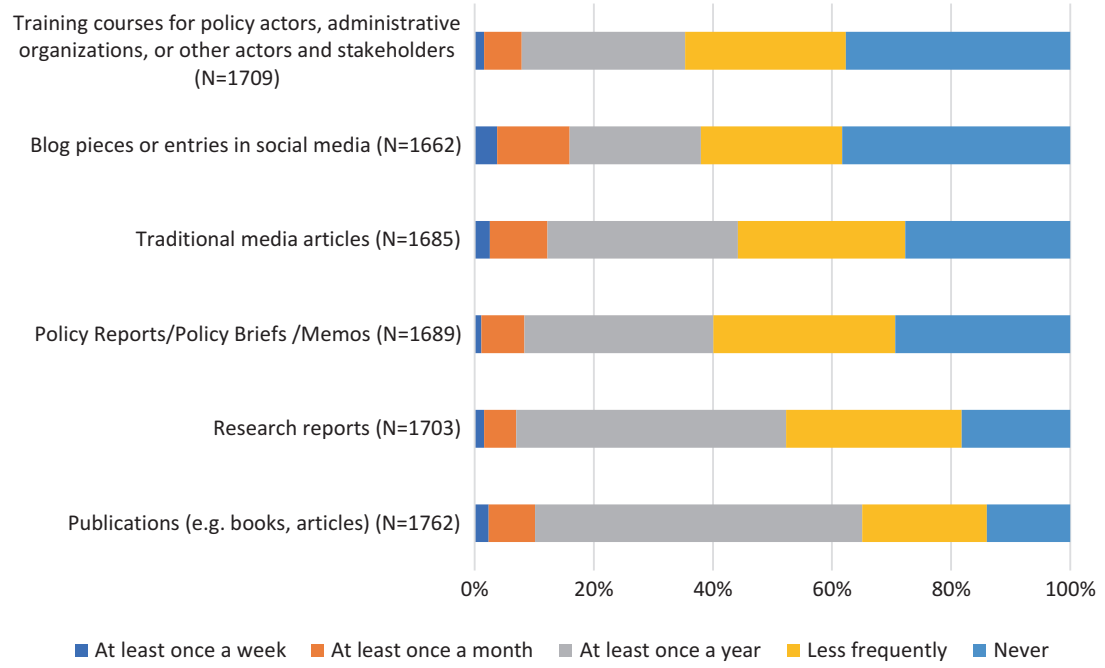

Fig. 16.6 Channels of policy advice. (Source: ProSEPS survey data)

These different channels relate also to the formal or informal nature of advice giving, even though these may be somewhat ambiguous concepts. Here, we refer to the extent to which an advisory relationship is formally organized and structured or contained in a contract or arrangement. Research reports or training courses will ensue more often when some formal arrangement between the adviser and recipient or client is set up. By contrast, blogs and media articles are more fluid and contain pieces of advice or advocacy in a more indirect and informal way. Academic publications may be harder to pinpoint in that they may be formal given the review and release process they often involve, but as channels of advice they may flow more informally and indirectly towards the reading audience or specific targets. Overall, political scientists mostly deliver advice both formally and informally, with some emphasis on informal ways. This is consistent with the relative prominence of opinionating as a type of advice.

\subsubsection{The Receiving End}

The end point of the flow of advice is the recipient. This may be an organization with which a structural arrangement is made, it can be a client of advice made ad hoc or it can be a group or organization at some more 
distance from the political scientist but which appears in the chain of communication. Figure 16.7 contains, again with pooled data, the main recipients of advisory activities of political scientists in Europe. While also organizations at the international or supranational stage are served and targeted with political science advice $(24.2 \%)$, most knowledge and information traffic flows to actors in the policy process at the national level. By and large, the two relatively most attended recipients are civil society organizations and citizen groups (44.8\%) and civil servants (41.2\%). In a way these are the most distinct types of actors, in that the former are much active in the public arena, while civil servants may be considered the least publicly oriented and exposed part of the government machinery. Private and corporate organizations are the least targeted recipient across European countries (18.3\%). Advisory bodies do not appear prominent either, certainly compared to think tanks which may incorporate not only scientific facts but also viewpoints and normative stances that political scientists want to express. Political parties and their executive and legislative branches take a middle position (all at or just below 30\%).

These percentages hide variation across countries. The policy advisory systems of Belgium, the Netherlands, the United Kingdom and to a lesser

Other civil society organisations and citizen groups

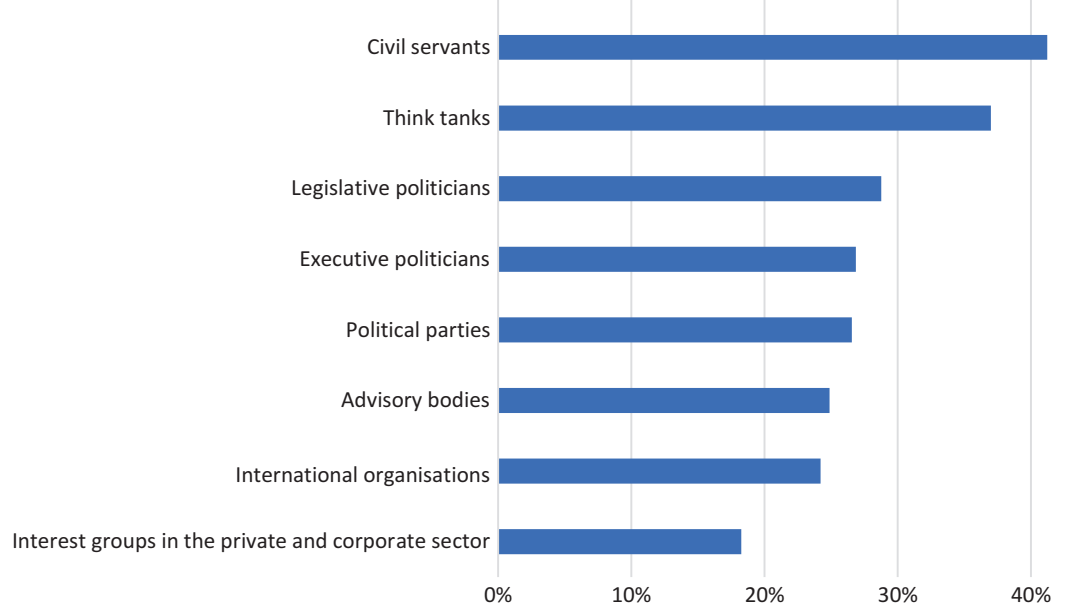

Fig. 16.7 Recipients of advice $(N=2354)$. (Source: ProSEPS survey data) 
extent also Denmark, Norway and Spain seem to contain wider access points to political scientists than the European average. For the other countries in this book the percentages of recipients mentioned are lower. This corresponds to a higher or lower proportion of active advisers within the political science communities in these countries, and to the size of the groups of experts and opinionating scholars. In countries with a comparatively less actively engaged community of political scientists, some specific recipients are visible on the demand side or are targeted. In Albania and Hungary, for example, international organizations and civic interest groups interact with political scientists more often than other recipients, and in Turkey also think tanks take their knowledge or advocacy messages as an indirect route for making political scientists' voices heard.

When looking more specifically at prominent types of recipients, we see patterns that can inform us more about the position of political scientists within the domestic policy advisory system. Civil servants are very important recipients of advice in Belgium, Denmark, Norway, the Netherlands and the United Kingdom. Also frequent interactions appear with the legislative and executive branches of political parties as well as with private and public interest groups and policy advisory bodies and think tanks. In the Netherlands, Denmark, the Dutch-speaking part of Belgium and the United Kingdom, formal advisory bodies are important intermediaries of political science knowledge to the government, but they are not in Spain. The mix of this group of countries may suggest that advisory roles do not only come with a specific policy-making system, such as a neo-corporatist and consensus model that entails many access points. The position of political scientists in the policy advisory system may be influenced by broader political, social and economic interests and trends such as politicization and more public attention to political issues, giving rise to more demand for knowledge in this field, and supply whenever political scientists are outreaching.

Likewise, France and Germany have different systems, but they both display comparatively lower levels of intensity of interactions between political scientists and recipients of their advice. In both France and Germany, civil society groups are the most frequently mentioned recipients and private and corporate interest groups seem to be the furthest removed from the realm of political scientists. But civil servants appear much less prominent in Germany than in France, while for political parties we see the opposite. Political scientists are located selectively in these countries, and this also may indicate how the policy advisory systems 
develop. The relatively low degree of interactions between political scientists and civil servants in Germany may be surprising given the bureaucracyoriented tradition in policy making in this country. In Italy, political parties and their branches are connected to political scientists at a level close to the European average, but there is more emphasis on think tanks and civil society organizations, and less on civil servants and advisory bodies. This too may indicate development in the policy advisory system: moving from the classical model of 'partitocrazia' and institutions formally associated to policy making towards civil society and independent centres for knowledge and ideas not connected to the political system. Political scientists display a similar tendency in Turkey in their connections for delivering advice, with emphasis on civil society organizations and think tanks.

A final dimension related to recipients is the level of governance at which advice by political scientists is delivered. When looking at the intensity of contact with types of recipients, it is not surprising that on average political scientists focus primarily on the national level (53\%). Subnational government or other actors at that level follow at some distance $(30.1 \%)$, and the international level (14.6\%) and the European Union (13.3\%) are the least attended, even though the difference becomes smaller when we take the percentages for EU and international together. As with recipients, countries vary considerably around the mean scores. This is mostly the case for relationships of political scientists within the domestic policy advisory system. In France and Turkey, the distribution of attention to national and subnational recipients is at the European average. The emphasis on national level recipients is higher in Albania, Denmark, Hungary, Norway, the Netherlands and the United Kingdom, while in Belgium, Germany, Italy and particularly in Spain the subnational level is more prominent than on average in Europe. These two groups of countries fit neatly into the distinction between unitary and federal states. The constitutional features of the political system thus mirror the advisory orientation of political scientists in most of the countries analysed in this book. In France and Turkey, the subnational level also is visible in advising, which may relate to the relevance of local government.

EU-membership becomes visible in the orientation on the European level, as in most member states political scientists show interest in it at an average level, sometimes above it. Political scientists in Belgium show high interest in the EU, given the location of Brussels. High attention also applies to the United Kingdom (prior to Brexit, when the survey was conducted). In France there is less attention. Countries outside the EU 
system all show lower levels of attention, except Albania. When taking also the international level into account (beyond the EU), differences between countries become more marked. Political scientists in the UK stand out for their international orientation in advising, as do political scientists from the much smaller community in Albania. Also Norway stands out, but negatively, in that the reputation of the country on military and peace research does not become visible in the proportion of scholars attending to the international level of advising. The regional role of Turkey in international relations also does not speak from the findings. Figure 16.8 presents for the 12 countries the emphasis on subnational relative to national level advising and on international level relative to national advising.

\subsubsection{Topic Areas of Political Scientists}

The occasional publicly oriented academic from the disciplines of economics, philosophy and sociology may quite comfortably speak on political matters (s)he has not studied. Van Parijs (2021) calls such an academic an inexpert responsible. Political scientists appear more cautious in such wide topic engagement. What may be expected from political scientists is that whenever engaging they do this primarily on subjects and issues close to their knowledge basis. The analysis of the substantive content of advice uses the topic classification system of the Comparative Agendas Project, distinguishing 21 main topic categories. In these, the structure and operations of government (including democratic and electoral reform) and international relations are the two fields closest to the body of knowledge of political scientists, as they are the main objects of study. But it is important to appreciate that the object of political science is not just institutional design or redesign, but also the policy-making process, in which any other topic can be involved. Thus political science knowledge includes representational, participatory, decisional and administrative aspects of policy problems. These policy problems themselves can range from migration to technology, civil rights to urban planning and from cultural to economic issues of the welfare state. The process element becomes a more relevant subject of advice as the nature of problems get more 'wicked' and policy makers face risks of support, legitimacy and accountability, or where other stakeholders need advice for having influence.

Taking these points into account, the main two topic areas are indeed about the core knowledge of political science: government and public administration $(30.8 \%)$ and international affairs including the European 


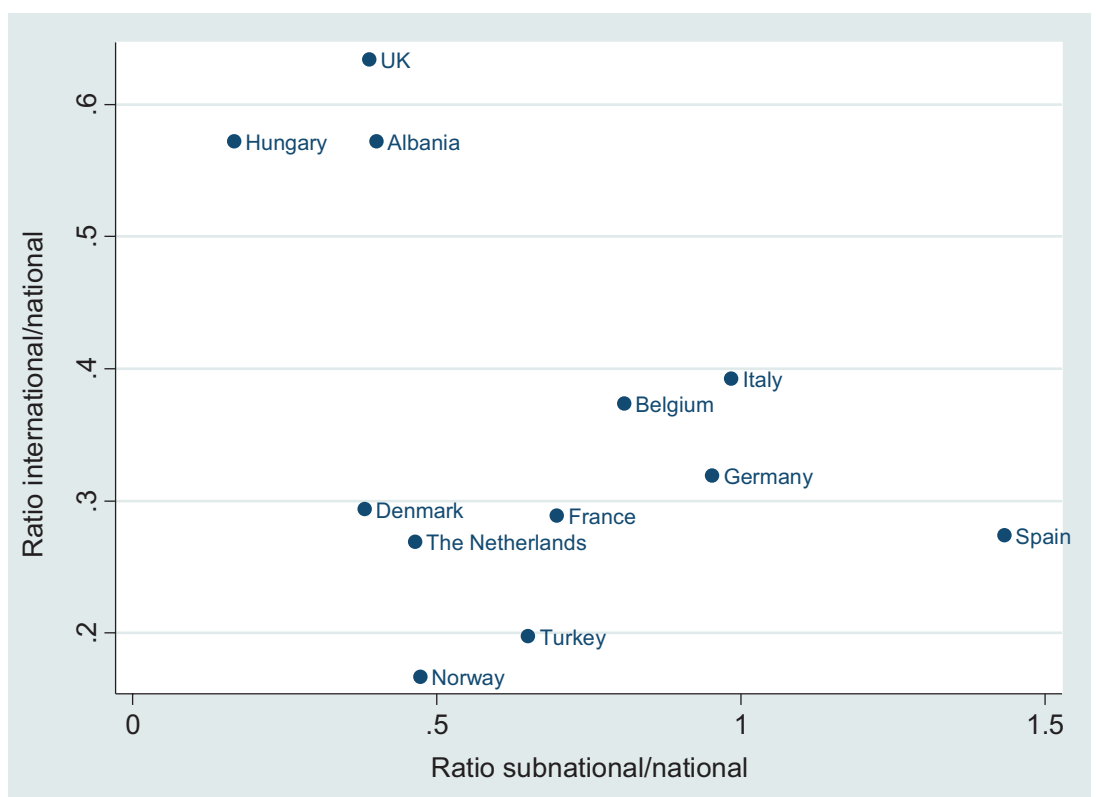

Fig. 16.8 Orientation on levels of governance. (Note: Axes represent the respective ratios between the percentage of respondents in each country declaring to provide policy advice at the subnational or international levels relative to those declaring to provide advice at the national level. For example, in Spain the percentage of those providing advice at the subnational level represent 1.4 times that of those who declare to provide advice at the national level, while the international level is just 0.18 times that of the national (and subnational) level. By contrast, political scientists in the UK place much more emphasis on the national relative to the subnational level, and also have a relatively strong orientation (ratio of 0.65 ) on the international level. Source: ProSEPS survey data)

Union (27.6\%). These are followed by some major policy themes: civil rights and gender, migration, education and social welfare. Other major public policy topics such as health (relating to pandemics-but note the survey was taken prior to COVID-19) or environment and energy (relating to climate change) appear niches of smaller groups of political scientists. Figure 16.9 presents the topics from most frequently addressed to the ones with the lowest attention. 
The policy agenda of most national or subnational governments and international or European institutions usually displays a distribution of attention where priorities are visible. These priorities shift over time, and making such shifts may be risky or costly, but they happen (Jones \& Baumgartner, 2005). In the same way, advisory topics appear as an expression of attention of political scientists. If we called this an 'advisory agenda' it would be important to realize that this agenda is not endogenous to the scholarly community but emerges in close interaction between academia and the political and social environment. It emerges in response to demand from practitioners and also results from what scholars in this field have in supply or believe they must actively put forward. The topic rank order is thus not static, even though the political agenda will shift more often and more drastically than the advisory agenda of political scientists. Just as economists, environmental scientists or legal scholars, political scientists have their realm of knowledge and expertise to which some topics are more central than others. The respondents to the ProSEPS survey indicated that their main field or subfield of expertise is political science $(60 \%)$, public policy $(28.5 \%)$ or public administration $(21 \%)$, with low percentages for specific subfields in which they may have become specialized as academic political scientists. Still, as Fig. 16.9 shows, nearly all fields of public policy are within the scope of political scientists. Topics attracting less attention in advising are addressed not only by specialized political

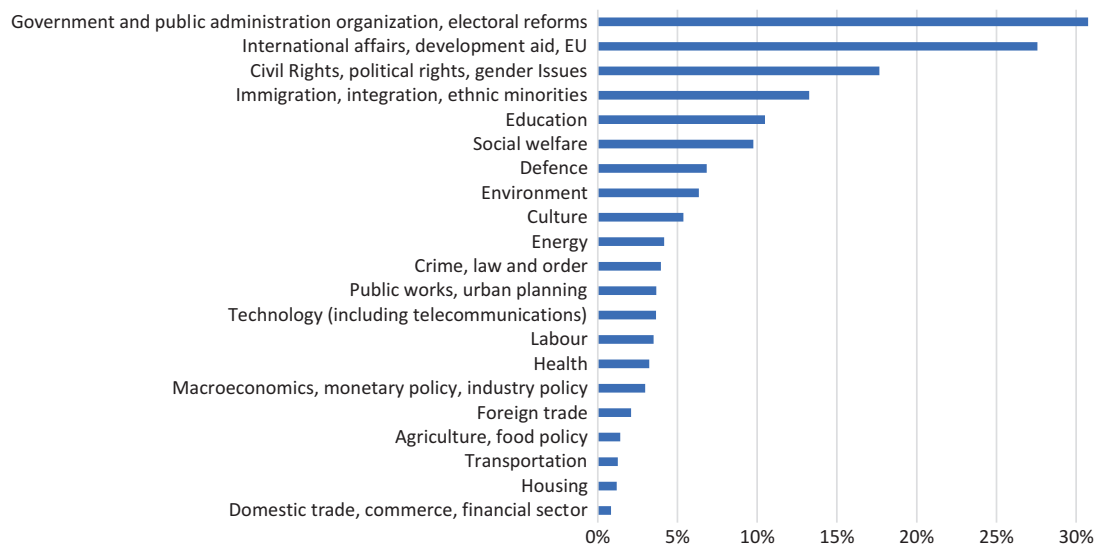

Fig. 16.9 Topics of advice $(N=2354)$. (Source: ProSEPS survey data) 
scientists but also by generalists indicating political science, public policy or public administration as their main field in the discipline.

In the same way that the policy agendas of countries vary, there is some variation in the advisory topic listings of political scientists between countries. Next to the pooled data, the specific topic listings of advisory activities also are available for 12 countries included in this book. While the primary knowledge home basis and focus on average for all countries, government and public administration is not the most attended theme of advice in Germany, Hungary and the United Kingdom. Demand and supply of advice in Hungary show busier traffic on social welfare issues, and this is international affairs in Germany and the United Kingdom. By contrast, more than average attention for government and public administration we find in the Netherlands (51.2\%), Belgium (46\%) and Spain $(42.1 \%)$, while Italy is at the average level, Norway somewhat below, and Turkey (21\%) and France (19.7\%) fall considerably below it. Social welfare scores higher in Denmark and Spain. Political scientists in France apply their knowledge to many different topics - the distribution of attention between them is more even than in most other countries. In Turkey, the fields of civil rights and gender, migration, ethnic minorities and culture together are the largest theme of advice, with 37\% almost twice as much attended to compared to government and public administration. This also is the case when including the topic of social welfare in Hungary.

One reason for the higher level of attention to government and administration in Belgium and Spain may be connected to issues around the federal state. We already saw that in these countries, the subnational level of advice is equally prominent or even more prominent than the national level. In the unitary state of the Netherlands, democratic and administrative reform are almost constantly on the political agenda (with $51.2 \%$ it has the highest score comparatively), and their salience in advising relates to the multiple attempts to depoliticize decision making. As a main topic, international relations shows the least variation in attention in advice across the countries in this book (between $17 \%$ and $30 \%$, compared to $17.7 \%-51.2 \%$ for government and public administration). This does not imply however that political scientists in these countries all venture to the international stage for advice, as more often they advise their own governments on this topic. This applies particularly to Germany, where international relations is the most prominent advisory topic, but as we saw there are less than average connections to international or European institutions 
for delivering this advice. Also in France and Norway, the part of the political science community specialized in international or European affairs is not strongly oriented on exporting their knowledge for advice.

\subsection{Political Scientists in the Policy AdVISORY SySTEM}

The different dimensions of advising help in mapping the ways in which political scientists across countries in Europe are oriented when engaging in advisory activities. It is a combination of history, institutional design of the political system at large and characteristics and trends within the policy advisory system.

History plays a part in viewpoints and motivations for engaging or staying at a distance. In Germany this appears to have two different effects, one is a concern and 'watchdog function' for the state of democracy engrained after World War II. Despite the salience of the EU for this country, political scientists are comparatively strongly oriented on domestic levels of governance. The other effect is the tradition of autonomy of academia, which draws scholars more into its inner sphere. Hence Germany has more pure academics than the European average. In Denmark, it may be the strong tradition of positivism in political science that produced the very large proportion of experts, with emphasis on evidence over opinion or advocacy. This tradition appears more visible in Denmark than in Norway, the other Scandinavian country highlighted in this book. Furthermore, the transition away from communism in the 1990s in Easter Europe is another historical factor that provides context for advisory orientations and behaviour of political scientists, one of which is advisory participation in the transition process itself. But the broader survey results and the chapters on Albania and Hungary do not point into one single direction. One part focuses on the domestic institutions and public arena, another part of the political science community feels more comfortable reaching out internationally. This also applies to political scientists in Turkey, who experience a different kind of regime change. But the use of international venues is limited to part of the political science community, it is not a mainstream orientation. Another historical factor with changes in its impact is the 'partitocracy' (Cotta, 2015; De Winter et al., 1996) in countries such as Belgium and Italy, where political parties are less prominent as recipients of advice than may be expected given this 'partitocratic' 
legacy. In both countries, parties are more important access points for advice via their executive and legislative branches than via the party organization. In this way, the lower level of prevalence of parties as such makes the two countries stand out less in a comparative perspective on advisory activities of political scientists.

\subsubsection{State Structure}

What appeared more clearly and unequivocally from the comparative discussion of advisory dimensions is the state structure, federal or unitary, and to a lesser extent also EU-membership, in the orientation on levels of governance. Federal countries attract more advisory attention of political scientists to the subnational level. Political scientists in seven out of the nine EU-member states included in this book deliver advice at the European level of governance more than average. And they also do this in the wider international environment. But not the two largest EU-member states France and Germany, where knowledge of the European Union and the international stage of politics are delivered more at the domestic level to recipients. Here, one line of argument could be that in larger countries the scholarly community of political scientists looks more inward at domestic recipients for advising and in small countries it is more outward looking, but the United Kingdom does not fit this pattern. And while Albania is the smallest country analysed more in detail in this book, the route for political scientists towards international arenas of advice is quite selective.

\subsubsection{Trends}

The country chapters placed political scientists as a category of academics in the context of the domestic policy advisory system, including advisory connections to the international or European stage. Exporting knowledge to foreign governments, international organizations or think tanks may come from push or pull factors, as for instance in Hungary and Turkey where tensions rise between academics (and political scientists in particular) and the political regime. The prominence of civil rights, migration, ethnic minorities and cultural issues on the advisory agenda of mostly opinionating scholars also is an indication. Next to opinionating, expertise may also follow an outside route by being transferred indirectly via international actors for building up capacity and a policy relevant body of 
knowledge, as in Albania. But the national communities of political scientists not only vary in their international engagement. They also take different positions at the intersection of academia, the internal sphere of government and the arena of public and private organizations, groups and the broader audience.

The empirical patterns on the dimensions of advising help placing political scientists in the policy advisory system of their country. Most countries show prominence of recipients in the arena of civic, nongovernmental and to a smaller extent also private organizations and groups. These countries are not only the democracies with a recent tendency towards authoritarianism, but also those where this broad arena is more structurally involved in policy making, as in Scandinavia, Germany and the low countries with their corporatist legacy. With respect to the internal government sphere, countries vary in the prominence of bureaucrats, and somewhat less in the specific intersections of academics with executive or legislative politicians and political parties. Overall, parties are less prominent users of knowledge than often assumed, in particular in the two typical cases of 'partitocracy' in this book: Belgium and Italy (Cotta, 2015; De Winter et al., 1996). The governmental sphere in many countries, of all types, has seen considerable externalization of advice, opening a window for political scientists along many other categories of experts. But what stands out from our findings on the topics of advice is that in some countries this externalization of advice happens less for the most essential theme of political science knowledge: the structure and functioning of government and public administration. While civil servants are prominent recipients in France and the United Kingdom, they in particular seem to resist knowledge transfer by academics on the fundaments of their own organization and functioning. The Grandes écoles, Oxford and Cambridge already taught them about this.

With these bureaucratic reservations as an exception, externalization in almost all countries brought more access points for academic political science advice. But politicization of science and advice also increased in most countries. This has a qualifying-or sometimes disqualifying-effect on academic political science knowledge in the policy process. And this factor in turn has effect on the position and role of political scientists within the advisory system. Some may withdraw or remain in a role as pure academics, others keep speaking the factual truth to power as experts, while still others more openly voice opinions or advocacy. Public intellectuals may be the most influential, but they are few. 


\subsection{Revisiting the Simple Model of Advisory Roles}

Now that we have taken a deeper and comparative look at the dimensions of advising, it is time to revisit the simple model of advisory roles and see how our findings may inform its further development. This is relevant not only for understanding the advisory activities of academic political scientists, but for the analysis of advisory relationships of academics more generally. The distinction between pure academics, experts, opinionating scholars and public intellectuals appeared useful for mapping academic views and external behaviour and comparing countries. But each of these four ideal types may contain some variation in profiles.

We saw that about one-third of the political scientists never takes initiative for bringing messages into the traditional or social media. While this is a defining characteristic of the pure academic (and to an extent of the expert as well), a more passive orientation still can include exposure from time to time. A pure academic may receive journalistic calls for explanation or interpretation on a matter on which she or he is knowledgeable. Such exposure may be connected to a news item or be published on the science page of a newspaper. It is not advice, opinionating or advocacy. The rise of relevance and impact criteria in fundamental research funding also increases the response from academics to invitations for exposure and public visibility (Smith et al., 2020). This becomes clear when analysing the involvement of political scientists in media debates via interviews or requested interpretations or comments on news items, presented in Fig. 16.10.

Pure academics are less visible, but not invisible, in the media. Also experts do feature in media debates, with emphasis on providing evidence. Conversely, if opinionating scholars and public intellectuals may be expected to be very active or even passionate about bringing their messages into the public sphere, media are not the only venue used by them. Both categories contain a significant percentage not participating in media debates. In short, exposure to the media happens in all role types, but it differs in degree. It must be distinguished from advisory or opinionating activities. One group of political scientists may have broad repertoire of active engagement in which the media are just one venue, and for another group some visibility may help strengthening the scholarly reputation.

Even political scientists who shield themselves off from public exposure are not void of values in their choices of research subjects and their orientation on the phenomenon they want to understand. Studying 


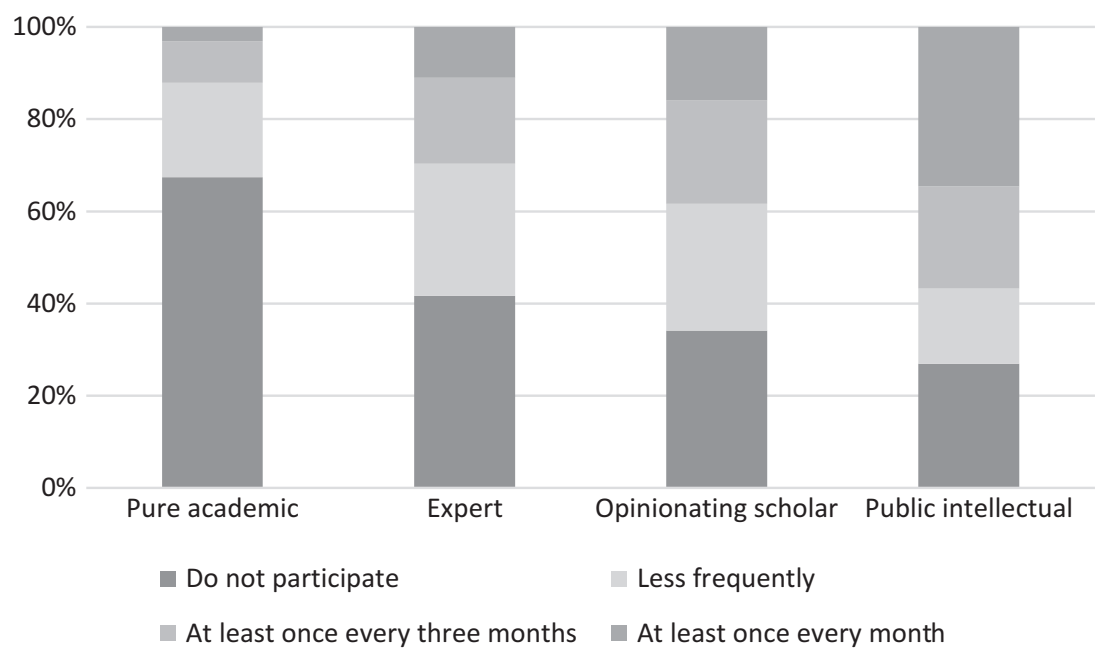

Fig. 16.10 Involvement of role types in media debates $(N=2354)$. (Source: ProSEPS survey data)

bureaucratic processing or the way an electoral system functions not just springs from scientific curiosity but often derives from some concern, or at least, an appreciation that administrative or representative matters have an impact on the political order and the state of democracy. In such cases, the normative underpinnings of pure academics are more implicit compared to their colleagues who are active externally to the university. As Pielke $(2007$, p. 7$)$ notes, scientists always must make a choice on how they relate to the decision-making process. For this reason, he speaks of 'stealth issue advocacy' $(2007$, p. 3$)$ that comes with preferences for research topics and analysis of the causes of problems. Next to the public visibility of political scientists, also, underlying values make that all role types have common properties. And as with visibility, the variation lies in the degree to which this is expressed.

Some variation within the role types, so the extent to which a political scientist is a 'typical' expert or a 'typical' opinionating scholar and so on, comes with the intensity of activities used as indicators of the ideal types. As pointed out in Chap. 3, we used a threshold approach in order to distinguish the types empirically. But beyond the threshold, some political scientists of a specific role type do their external work with more fervour 
than others. For this reason, we should see the categories as areas on a continuum, where one type flows over into the next. And the profiles are also more mixed when we consider the patterns found on the additional dimensions of advising. Take the formality or informality of advice. In Chap. 2 we argued that the expert may profile mostly (but not exclusively) in formal fashion, while the opinionating scholar would be inclined to engage more informally (but not exclusively). Our caution with drawing specific profiles for the advisory role types in Chap. 2 appears justified, as in Fig. 16.11 we can see that the formality or informality of advice connects to the role types only to a degree. Experts are relatively more often oriented on formal advising arrangements than the other two types, but experts also are more often mainly or entirely informal. Conversely, the opinionating scholar is much less frequently informal than a specifically profiled role type would lead us to expect. The mixed repertoire of the public intellectual, with more than $60 \%$ of this type of political scientists combining formal and informal ways of advising, conforms to what could be expected for this profile. The reality is one of varying degrees between the role types, and not always in the direction of a theoretical profile.

Similarly, the recipients of advice are less exclusively connected to the role types than a theoretical argument would suggest. In such an argument experts would link mostly to civil servants and advisory bodies for

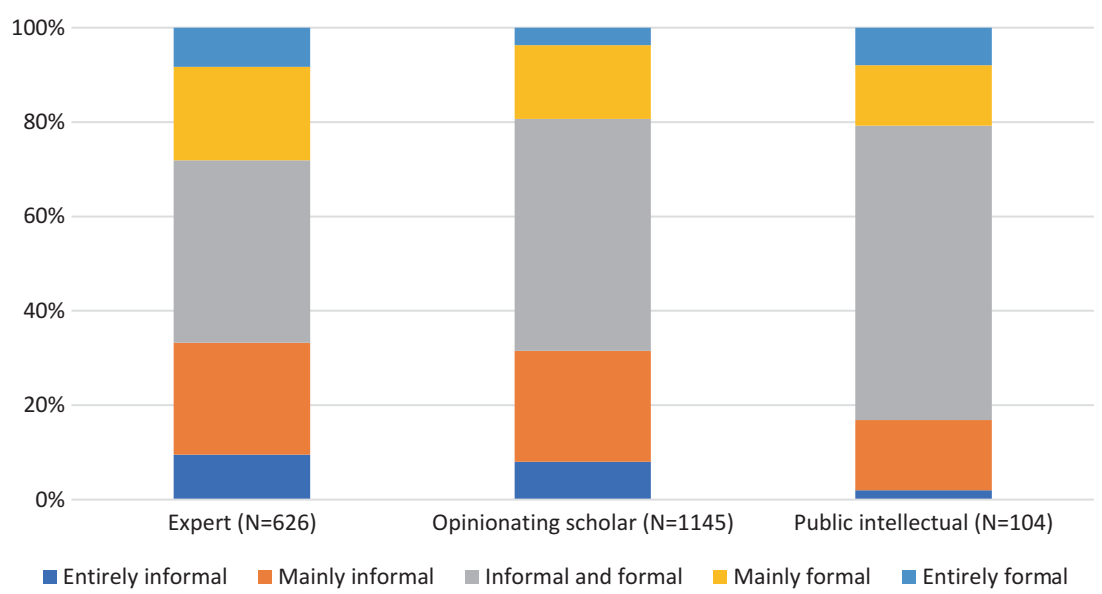

Fig. 16.11 Role types and formality or informality of advice. (Source: ProSEPS survey data) 
technical knowledge and information exchange, and opinionating scholars would profile more with (party) political actors and civil society organizations and groups. Figure 16.12 demonstrates that, as with the formality or informality of advice, public intellectuals fit the theoretical profile of allround advisers. But experts are not so selective in their access points for advice and display, at a lower level of intensity, a pattern of orientation on recipients similar to opinionating scholars. Experts only have a slight preference for bureaucratic actors over political actors, which is the reverse for their opinionating colleagues. External stakeholders already were found to be prominent as a category of recipients, indicating they are directly relevant to policy making or entered the scope of political scientists when party political actors in government or parliament have become less receptive to their advice and knowledge. The prominence of external, social stakeholders appears for all three types of advisers.

While the findings for these different dimensions of advising often point into the direction of what could be expected to be the role profiles, it is also clear that these are not cases of straightforward pattern matching. The findings tell us two things for the evaluation of the simple model of advisory roles. The first is that advising as an external activity of political scientists, or of any group of academics, is truly multidimensional. Advisory

$100 \%$

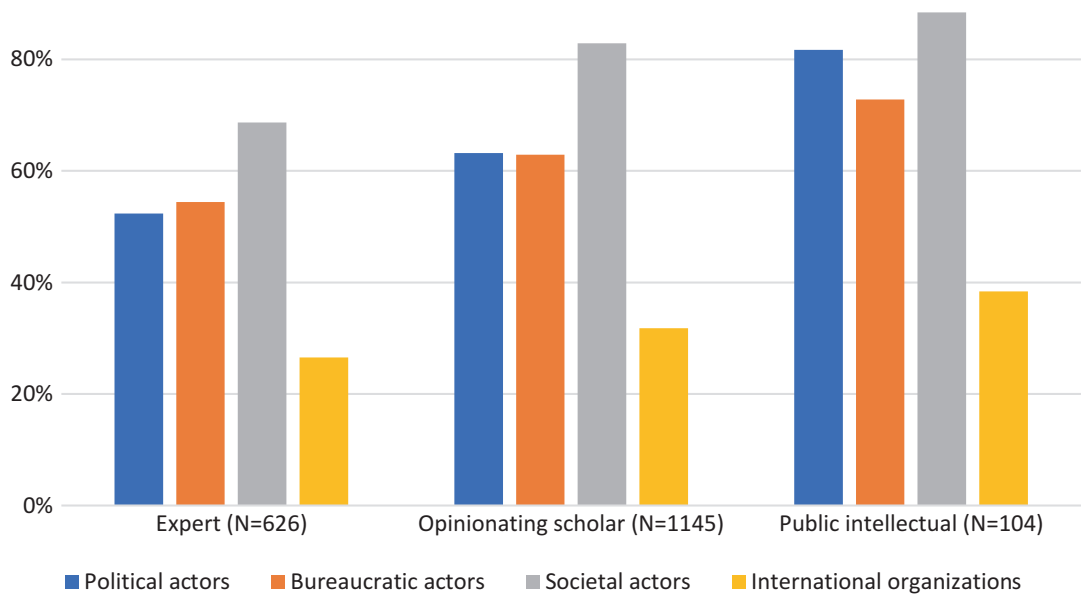

Fig. 16.12 Role types and recipients of advice. (Source: ProSEPS survey data) 
role types include a broader range of choices than can be contained in a simple theoretical model, and the choices that occur are not always mutually exclusive between the roles. For advisory orientations and activities of academics to be better understood and to make theoretical progress, it is necessary to further investigate the dimensions of advising. The range of recipients, for example, is not static but depends both on the orientations of academics and on how broader political and social trends impact on the demand for scientific evidence in the policy process. The state of knowledge about this can be improved not only by large scale survey research but also by well selected case studies, comparatively or focusing on typical or critical cases of academic policy advice processes. The dimensions of advice and reasons for engagement (or abstention) can subsequently be connected also to impact the use or neglect of political science knowledge and advice. They matter also for the competencies and skills of the students we teach and train.

The second conclusion we can draw from the analysis is that the four role types with variation between and within them are positions on a continuum. One type flows into the other type as members of the population shift in their characteristics along the different dimensions of advising. Between abstention and passionate advocacy by political scientists there are many points on the dimensions of advising, between no activities and continued engagement, no visibility and spotlight, hidden and open channels, recipients within government or public targets in society, and between factual work and political or social beliefs as a driving force. The points on these dimensions may not all co-vary. Patterns between them can be mixed as we saw when comparing the role types to choices about formality or informality and types of recipients. But by and large, all dimensions open up to disclosure and exposure of political science knowledge and ideas.

Figure 16.13 presents a multidimensional model of advisory roles in which our four ideal types are elaborated into, relatively from each other, more closed and discrete or more exposed and oriented on the societal arena and public channels.

Thus more extravert pure academics differ from their introvert colleagues in some degree of media visibility. Likewise, exposed experts have a broader forum of knowledge delivery than their discrete colleagues, and advocates venture into the societal arena with all kinds of stakeholders more than their counterparts providing opinions at some interval. The public intellectual stands apart as the single most exposed on all dimensions of advising. 

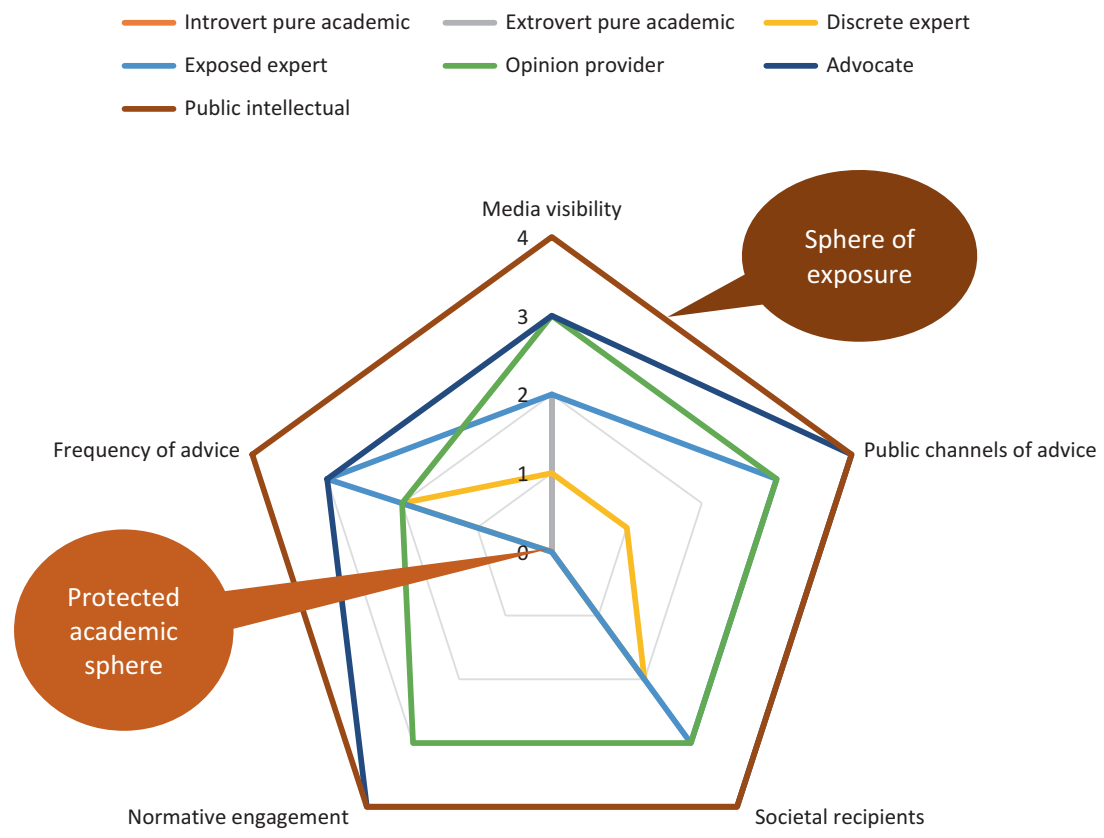

Fig. 16.13 Multidimensional model of advisory roles. (Source: Author)

\subsection{OUTLOOK}

Academic political scientists in Europe are quite extrovert in their attitudes and activities. They live part of their professional life outside the 'ivory tower' of the university, engaging in policy advisory activities of all kinds. The vast majority of university-based political scientists across the countries in this book responds to advising requests and delivers opinions with lower or higher frequency. Few are all-round public intellectuals, most develop a modest portfolio of external activities bringing knowledge and viewpoints to all kinds of users, or potential users. Opinionating scholars are most visible, both in terms of the proportion of political scientists engaging in this activity and in terms of the channels and messages used. At the same time, most also are careful or cautious about their messages. Expressive activity is not their primary business. Backing up advisory statements with evidence is important. When evidence and facts are the 
primary tools of the trade, political scientists profile as experts, the second largest group in the scholarly community of political scientists.

The field of specialization within the discipline and experience in political or administrative office draw some political scientists more into advisory work than others. The respondents from the 12 countries in this book occupy more space in public administration and public policy compared to the overall survey, and this may make them more active in advisory roles. Experiences in political or administrative office before or during the academic appointment similarly may influence advisory work. Most countries where political scientists have a higher than average experience in such office external to the university also have a lower proportion of pure academics (Albania, Norway, the United Kingdom, the main exception being Hungary, see Fig. 3.7 in Chap. 3), and conversely, lower than average experience rates in external office go mostly with more prominence of pure academics within the national political science community (this is most visible in France, Germany and Italy). The domestic policy advisory system is the context where these substantive specialization and professional experience factors bear on advisory engagement.

Despite variation between countries, the general background variables relating to individual characteristics of respondents make a large difference to the extent and nature of engagement. Age, gender and type of employment contract each have a strong predictive effect. Age and status of employment relate to the professional life cycle, in that older, more experienced scholars with a permanent academic position are more active in advising than their younger colleagues at the department of political science. These factors interact with gender, but the relevance of gender for advisory engagement is also particularly strongly socially constructed. Female political scientists abstain more often, and when engaging they take an expert role, staying closer to evidence and less reaching out to the public environment. This apparent gender gap occurs widely across all spheres of professional affiliation, and it requires more systematic attention within the academic political science community.

Representative issues at the sending end of the chain of knowledge production and dissemination are not the only bottleneck. At the receiving end, whatever the degree of welcoming, it is the actual use of advice that must be part of attempts and strategies for relevance and impact. This book did not deal with knowledge uptake and use in policy making, but for political scientists it is important to attend to this part of the story (Bandola-Gill et al., 2021). As Head (2015, p. 7) found, arranging 
ongoing interactive relationships with receivers appears more effective for knowledge use than unilateral transfers by academics. While part of the engagements with policy makers can be considered arranged, especially the more formal ones, such arrangement is not a given. This is empirical research ahead, and it may build on the work of Talbot and Talbot (2015) and others such as in the project on Governments, Academics and Policymaking (GAP). Use of advice by political scientists also depends on the roles played by other advisory actors such as consultants and on the available slots within advisory bodies for political scientists. Other scientific disciplines also may be a competitor in advising involvement, such as economics and law.

The internationalization of academic life reinforces discovery and scientific progress. But it also may have an inverse relationship with active advisory roles, because internationalization of scholarly work draws much of the attention into it. The international mobility of scholars may reduce their capacity and access points to recipients. As we saw, recipients of political science advice are predominantly domestic organizations. For a knowledge migrant working in academia, it takes time to settle down in a national policy advisory system. International profiling and domestic relevance may show a tension. And as we saw, advising at the international level overall is least frequent compared to the national and subnational level. Thus socialization within a country is important for advisory activities (even though the most internationally mobile scholars may be the ones active at the international level of advising).

As a matter of principle, the authors in this book did not take a normative point of departure by suggesting that one role type is superior to another. Pure academics are neither 'dysfunctioning' academic professionals nor are they the only true kind of scholars in the contemporary university system. Similarly, experts, opinionating scholars and public intellectuals are not, in themselves, loyal or disloyal, good or bad professionals for their university home basis. Neutrality towards the role types in this comparative analysis also is important because the national context of academic organization and the policy advisory system can nurture a particular role type and its further development more than another type.

But such neutrality does not mean indifference to values. Political science not only studies the authoritative allocation of values (Easton, 1965), the discipline itself also is loaded with values. This is as much true in countries where democracy seems stable and unthreatened as in countries where populism and authoritarianism in political regimes are gaining 
ground. It may be that unfree elections and persistently introvert and unaccountable behaviour of administrative organizations will make all or most political scientists signal that something must be done. But what scholars of agenda setting have called the hidden face of power (Bachrach \& Baratz, 1962; Lukes, 1974) is about all those less expressed and visible cases where political power has consequences for participatory and distributive issues. The choice of an object of research in political science can be driven by a concern, and what distinguishes political analysis from political reasoning is its systematic approach to evidence and argumentation.

This brings us to a final point about relevance of political science knowledge. Senn and Eder (2018) distinguish political, civic and professional relevance of political science. Given the size of the group of political scientists across countries in Europe that engages in advisory relationships with politics and the public, it is necessary to see how this political and civic relevance relate to professional relevance. Writing about foreign policy, George (1994) indicates how better awareness of types of knowledge produced by academics can help bridging the gap with policy makers. One lesson from this book project is that the professionalization of political science should include not only academic standards on theory testing or development and technical skills but also an orientation on how and why research topics are selected in the first place and how knowledge can be diffused more effectively and be brought to use outside the academic sphere itself. Compared to the already low percentage of pure academics among university-based political scientists, the proportion of purely academically oriented graduates when ending their master programmes is even considerably smaller. Some $95 \%$ pursue a career outside the university.

Connecting political and civic relevance to professional relevance clearly challenges what and how we instruct our students and have us think carefully about the competencies and skills they bring to their first environment of employment. To re-address Aristotle's typology of knowledge, graduate education in political science and its subfields should include techne and phronesis next to the episteme with which it is already much involved. To consider more systematically what works (techne) and what must be done (phronesis) may link knowledge and skills more strongly to the practice in which graduates will work. This is not a devaluation of academic education. Learning from analyses of engagement and locations within a policy advisory system and interactions with knowledge and advice as currency may be more oriented on practice, but it still is 
academic training. Thus graduate programmes, for example, may pay attention not only to data science as a technical approach to collection and management of large scale data, but also to issues of ownership and authority drawn from such data. Likewise, causal argument and empirical analysis help students build their evidence basis for any role as expert or affiliations that may involve problem solving or advocacy, but the capacity to switch between supply and demand sides in knowledge production and delivery does not come naturally. It requires that graduate students are trained for this boundary work. This would involve design thinking and skills of writing policy briefs and communication in diverse organizational or public settings. While much scholarly work is becoming increasingly specialized, the political and broader social reality in which knowledge circulates is taking a more sceptical position towards scientific knowledge, or sometimes even disqualifies it from a mindset that moved to 'posttruth' argumentation (Brans \& Blum, 2020). Against this turn of knowledge denial and alternative facts in the policy process, it is key to include strategies and approaches to effective knowledge in academic education programmes. For academic programme innovation, this means that political scientists are professionally trained in disclosing and communicating their knowledge to users of all kinds. But also the national and international associations of which many political scientists are members do well to take policy advisory skills serious. They also have a role to play for maintaining and strengthening the relevance and impact of political science to politics, society and the world of professions.

\section{REFERENCES}

Bachrach, P., \& Baratz, M. S. (1962). Two faces of power. The American Political Science Review, 56(4), 947-952.

Bandola-Gill, J., Flinders, M., \& Brans, M. (2021). Incentives for impact: Relevance regimes through a cross-national perspective. In R. Eisfeld \& F. Flinders (Eds.), Political science in the shadow of the state: Research, relevance, deference. Palgrave Macmillan.

Brans, M., \& Blum, S. (2020). From 'Speaking Truth to Power' to 'Evidence Free (d) Policymaking? The new faces of the science-policy Nexus. KULEUVEN Public Governance Institute. Unpublished paper.

Cotta, M. (2015). Partitocracy: Parties and their critics in Italian political life. In E. Jones \& G. Pasquino (Eds.), The Oxford handbook of Italian politics. https:// doi.org/10.1093/oxfordhb/9780199669745.013.4 
De Winter, L., \& della Porta, D. and Deschouwer, K. (1996). Comparing similar countries: Italy and Belgium. Res Publica, 38(2), 215-235.

Easton, D. (1965). A framework for political analysis. Prentice-Hall.

George, A. L. (1994). The two cultures of academia and policy-making: Bridging the gap. Political Psychology, 15(1), 143-172.

Head, B. (2015). Relationships between policy academics and public servants: Learning at a distance? Australian Journal of Public Administration, $74(1), 5-12$.

Jones, B. D., \& Baumgartner, F. R. (2005). The politics of attention. How government prioritizes problems. The University of Chicago Press.

Lukes, S. (1974). Power: A radical view. Macmillan.

Norris, P. (2020). The world of political science: Academic values, roles and experiences. In T. Boncourt, I. Engeli, \& D. Garzia (Eds.), European political science at 50. ECPR Press.

Pielke, R. A. (2007). The honest broker: Making sense of science in policy and politics. Cambridge University Press.

Senn, M., \& Eder, F. (2018). Cui Bono Scientia Politica? A multi-dimensional concept of relevance and the case of political science in Austria. Österreichische Zeitschrift für Politikwissenschaft, 47(3), 1-17.

Smith, K., Bandola-Gill, J., Meer, N., Stewart, E., \& Watermeyer, R. (2020). The impact agenda. Controversies, consequences and challenges. Bristol University Press.

Talbot, C., \& Talbot, C. (2015). Bridging the academic - Policy-making gap: Practice and policy issues. Public Money \& Management, 35(3), 187-194.

Timmermans, A., Pattyn, V., \& Van der Meulen, B. (2021). Political and social forces shaping political science and knowledge transfer in the Netherlands. In R. Eisfeld \& F. Flinders (Eds.), Political science in the shadow of the state: Research, relevance, deference. Palgrave Macmillan.

Van Parijs, P. (2021). La liberté academique et éthos universitaire. In V. Frangville, A. Merlin, J. Sfeir \& P.-E. Vandamme (Eds.), La liberté académique dans tous ses états. Editions de l'ULB. 
Open Access This chapter is licensed under the terms of the Creative Commons Attribution 4.0 International License (http://creativecommons.org/licenses/ by $/ 4.0 /$ ), which permits use, sharing, adaptation, distribution and reproduction in any medium or format, as long as you give appropriate credit to the original author(s) and the source, provide a link to the Creative Commons licence and indicate if changes were made.

The images or other third party material in this chapter are included in the chapter's Creative Commons licence, unless indicated otherwise in a credit line to the material. If material is not included in the chapter's Creative Commons licence and your intended use is not permitted by statutory regulation or exceeds the permitted use, you will need to obtain permission directly from the copyright holder. 